\title{
Functional comparison of antisense proteins of HTLV-1 and HTLV-2 in viral pathogenesis
}

\author{
Benoit Barbeau 1, Jean-Marie Peloponese ${ }^{2,3}$ and Jean-Michel Mesnard ${ }^{2,3}$ * \\ ' Département des sciences biologiques and Centre de recherche BioMed, Université du Québec à Montréal, Montréal, OC, Canada \\ ${ }^{2}$ Centre d'études d'agents Pathogènes et Biotechnologies pour la Santé, Université Montpellier 1, Montpellier, France \\ ${ }^{3}$ UMR5236, Centre d'études d'agents Pathogènes et Biotechnologies pour la Santé, Centre National de la Recherche Scientifique, Montpellier, France
}

\section{Edited by: \\ Françoise Bex, Université Libre de Bruxelles, Belgium}

Reviewed by:

Hidekatsu Iha, Oita University, Japan Noreen Martha Sheehy, University

College Dublin, Ireland

*Correspondence:

Jean-Michel Mesnard, UMR5236, Centre d'études d'agents Pathogènes et Biotechnologies pour la Santé, Centre National de la Recherche Scientifique, 1919 Route de Mende, 34293 Montpellier Cedex 5, France e-mail: jean-michel.mesnard@ cpbs.cnrs.fr
The production of antisense transcripts from the $3^{\prime}$ long terminal repeat (LTR) in human T-lymphotropic retroviruses has now been clearly demonstrated. After the identification of the antisense strand-encoded human T-lymphotropic virus type 1 (HTLV-1) bZIP (HBZ) factor, we reported that HBZ could interact with CRE-binding protein (CREB) transcription factors and consequently turn off the important activating potential of the viralTax protein on HTLV-1 5' LTR promoter activity. We have recently accumulated new results demonstrating that antisense transcripts also exist in HTLV-2, -3 , and -4 . Furthermore, our data have confirmed the existence of encoded proteins from these antisense transcripts (termed antisense proteins of HTLVs or APHs). APHs are also involved in the down-regulation of Tax-dependent viral transcription. In this review, we will focus on the different molecular mechanisms used by HBZ and $\mathrm{APH}-2$ to control viral expression. While HBZ interacts with CREB through its basic zipper domain, $\mathrm{APH}-2$ binds to this cellular factor through a five amino acid motif localized in its carboxyl terminus. Moreover, unlike APH-2, HBZ possesses an $\mathrm{N}$-terminal activation domain that also contributes to the inhibition of the viral transcription by interacting with the KIX domain of p300/CBP. On the other hand, HBZ was found to induce T cell proliferation while APH-2 was unable to promote such proliferation. Interestingly, HTLV-2 has not been causally linked to human T cell leukemia, while HTLV-1 is responsible for the development of the adult T cell leukemia/lymphoma. We will further discuss the possible role played by antisense proteins in the establishment of pathologies induced by viral infection.

\section{Keywords: HTLV-1, HTLV-2, antisense transcription, HBZ, APH-2}

\section{INTRODUCTION}

The human T-lymphotropic virus type 1 (HTLV-1) was the first pathogenic retrovirus to be isolated in humans (Poiesz et al., 1980; Miyoshi et al., 1981). This virus is the etiological agent of adult T cell leukemia/lymphoma (ATLL) and HTLV-1-associated myelopathy/tropical spastic paraparesis (HAM/TSP). Although an important number of individuals are infected by HTLV-1, only $10 \%$ will eventually develop pathologies (Barbeau and Mesnard, 2007; Matsuoka and Jeang, 2007). Leukemic cells in ATLL are mostly $\mathrm{CD} 4^{+} \mathrm{T}$ cells. One of the best studied associations between HTLV-1 and oncogenesis is the viral Tax protein, as demonstrated in primary $\mathrm{T}$ cells and various mouse models (Matsuoka and Jeang, 2007). It likely results from the capacity of Tax to activate multiple transcription factors and to induce genetic instability (Mesnard and Devaux, 1999; Boxus et al., 2008). However, Tax is often repressed in cells from ATLL patients (Takeda et al., 2004; Satou et al., 2006). Selective pressure mediated by strong antiTax immune response might justify the lack of Tax expression in ATLL cells (Hanon et al., 2000; Enose-Akahata et al., 2012). HTLV2 is closely related to HTLV-1 and shares most viral genes such as Tax and Rex but HTLV-2 is clinically distinct from HTLV-1 since it is not associated with any forms of leukemia (Feuer and Green, 2005). However, HTLV-2 can efficiently immortalize and transform T lymphocytes in vitro (Ye et al., 2003) and HTLV-2 Tax can immortalize human $\mathrm{CD}^{+} \mathrm{T}$ cells at higher efficiency than HTLV-1 Tax (Imai et al., 2012). Taken together, these data suggest that Tax expression is not sufficient for ATLL development and is thus dispensable at least for the late stage of leukemogenesis. Additional viral proteins obviously are thereby needed to play such a role. Indeed, growing evidence indicate that antisense transcripts produced from the $3^{\prime}$ long terminal repeat (LTR) of the HTLV-1 proviral DNA might fit such a role. These transcripts are involved in the production of the HTLV-1 bZIP (HBZ) factor in infected cells (Cavanagh et al., 2006; Murata et al., 2006). We have recently demonstrated that such antisense transcription also exists in HTLV-2-infected cells and permits the synthesis of the antisense protein of HTLV-2 (APH-2; Halin et al., 2009). This review will discuss the role of antisense transcription and resulting viral proteins in the development of pathologies associated with HTLV infection.

\section{ANTISENSE TRANSCRIPTS ARE PRODUCED FROM THE 3 ' LTR OF THE HTLV PROVIRAL DNA}

HTLV-1 and HTLV-2 are complex retroviruses sharing a similar genome structure with an approximate $70 \%$ nucleotide sequence homology (Feuer and Green, 2005). Like all retroviruses, they 
harbor essential genes for their replication, which include gag, pol and env. In addition to these genes, they harbor genes coding for the Tax and Rex regulatory proteins (Figure 1). Tax acts in trans to activate transcription initiating from the viral promoter in the $5^{\prime}$ LTR and Rex regulates viral gene expression post-transcriptionally by facilitating cytoplasmic shuttling of incompletely spliced viral mRNAs. HTLV-1 encodes the accessory proteins p12, p13, and p30 whereas HTLV-2 encodes the p10, p11, and p28 accessory gene products (Figure 1). Studies have indicated that these proteins are dispensable for in vitro infection and transformation of T cells but are important for the ability of the virus to infect, spread, and persist in vivo (Albrecht and Lairmore, 2002; Feuer and Green, 2005). Transcription of all these viral genes is dependent on the $5^{\prime}$ LTR region, which is segmented in three regions termed $U 3, R$, and $U 5$. The $\mathrm{U} 3$ region harbors important elements like the Tax-responsive elements (TxREs). A Tax dimer interacts with cellular Activating Transcription Factor/CRE-binding (ATF/CREB) proteins bound specifically to TxREs (Basbous et al., 2003b; Nyborg et al., 2010). The formation of such a complex on the $5^{\prime}$ LTR then serves as a binding site for the recruitment of the pleiotropic cellular coactivators p300/CBP through their interaction with Tax. Recruitment of p300/CBP to the viral promoter induces local nucleosome modification by histone acetylation and facilitates stable binding of components of the basal transcription machinery allowing the stimulation of viral transcription (Gachon et al., 2002; Luebben et al., 2010).

For a long time, all retroviral genes have been thought to be transcribed through the U3 region in the $5^{\prime}$ LTR of the provirus. However, the production of antisense transcripts from the $3^{\prime}$ LTR in HTLV-1-infected cell lines (Larocca et al., 1989) and the presence of a conserved open reading frame (ORF) in the complementary strand of the HTLV-1 provirus (Larocca et al., 1989; Gaudray et al., 2002) suggested the existence of viral mRNA of negative polarity. In 2002, we clearly demonstrated the existence of an antisense strand-encoded protein termed HBZ in HTLV1-infected cell lines (Gaudray et al., 2002). Further experiments by our teams and others have revealed that the antisense HBZencoding transcript was spliced and polyadenylated (Cavanagh et al., 2006; Murata et al., 2006; Satou et al., 2006; Yoshida et al., 2008) and that different HBZ isoforms could be produced, with one of them being the most abundant and dependent on a spliced transcript (Figure 1). In 2009, we also characterized a spliced antisense mRNA in HTLV-2-infected cell lines, involved in the production of APH-2 (Halin et al., 2009). This transcript is structured similarly to the HBZ transcript, i.e., it is spliced, initiates in the $3^{\prime}$ LTR at multiple sites, and is polyadenylated. The length of the intron and of the $5^{\prime}$ and $3^{\prime}$ untranslated regions is also similar to that of the HBZ transcript (Figure 1). These similarities could suggest that the expression of antisense transcription in the HTLV (and STLV) retrovirus family has been conserved among the different viruses. Indeed, we have recently confirmed the synthesis of antisense proteins from HTLV-3 and -4 proviral DNA (Larocque et al., 2011). On the other hand, unlike HBZ mRNA, we did not observe alternative splicing for APH-2, -3 , and -4 mRNAs (Halin et al., 2009; Larocque et al., 2011) suggesting that these retroviral antisense genes are likely producing a single isoform.

\section{HBZ AND APH-2 INHIBIT Tax-DEPENDENT VIRAL TRANSCRIPTION}

Initial studies highlighted the negative impact of HBZ expression on HTLV-1 replication by virtue of its capacity to inhibit Tax-mediated activation of HTLV-1 transcription (Gaudray et al.,

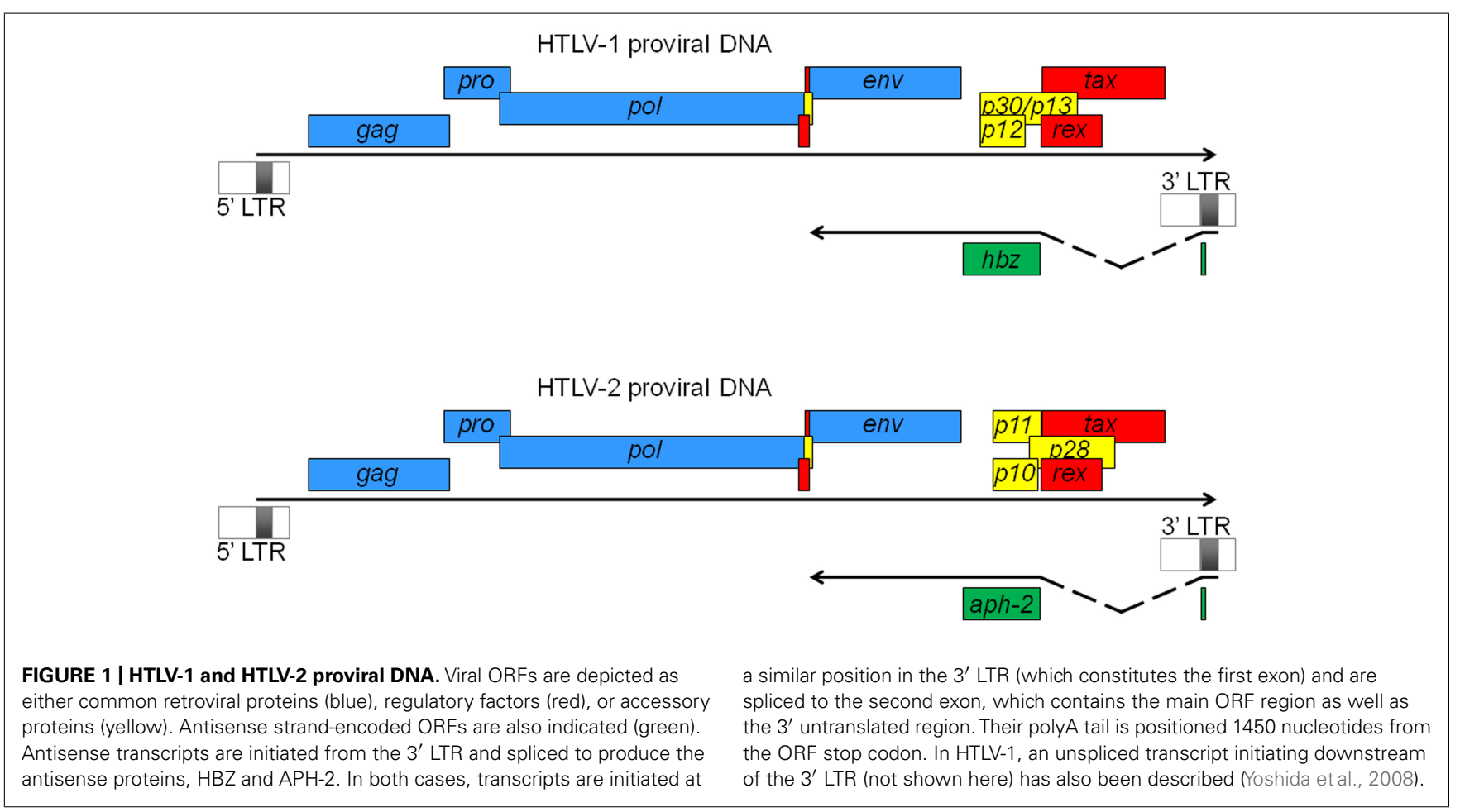


2002; Arnold et al., 2006). HBZ acts as a repressor of viral transcription by forming heterodimers with CREB, CREB-2, CREM, and ATF-1 that are no longer capable of binding to TxRE. HBZ is a nuclear transcriptional factor able to interact with ATF/CREB proteins (Gaudray et al., 2002; Lemasson et al., 2007; Hagiya et al., 2011) through its basic zipper (bZIP) domain (Figure 2), leading to inhibition of their DNA-binding activity (Hivin et al., 2005, 2006). Consequently, Tax cannot be positioned on the viral promoter and is thereby unable to trans-activate HTLV-1 transcription (Gaudray et al., 2002; Lemasson et al., 2007). Interestingly, APH-2 has also been shown to repress Tax-mediated viral transcription (Halin et al., 2009; Yin et al., 2012) by interacting with CREB. However, unlike HBZ, this interaction is mediated by the LXXLL motif present in the C-terminus of APH-2 (Figure 2; Yin et al., 2012). Interestingly, it has been shown that the repressive activity of APH-2 is less strong than that of HBZ. This difference in the inhibitory potential of both proteins might be explained by the additional interaction of HBZ with p300/CBP. Unlike APH2, HBZ possesses a transcriptional activation domain within its $\mathrm{N}$-terminal region (Figure 2) involved in an interaction with the KIX domain of p300/CBP (Clerc et al., 2008; Cook et al., 2011). In the context of viral transcription, we have demonstrated that HBZ could displace p300/CBP from the HTLV-1 promoter by competing with Tax for binding to the KIX domain (Clerc et al., 2008). Moreover, this mechanism appears more efficient than that of the ZIP domain in mediating repression of Tax-dependent viral transcription. On the other hand, additional reports have demonstrated that $\mathrm{HBZ}$ can activate cellular gene transcription through its interaction with p300/CBP (Kuhlmann et al., 2007; Polakowski et al., 2010; Macaire et al., 2012).

Analyses of transcription factors involved in the regulation of HTLV-1 antisense transcription showed that the Sp1 transcription factor was critical for its trans-activation (Yoshida et al., 2008; Gazon et al., 2012). We recently demonstrated that Sp1 enhanced antisense transcription by cooperating with the HBZ-JunD heterodimer (Gazon et al., 2012), which implicates the previously reported ZIP-dependent interaction between HBZ and JunD (Thébault et al., 2004; Figure 2). Thus, HBZ not only inhibits expression of other viral proteins such as Tax but also stimulates its own expression. While the majority of HTLV-1-specific CD8 ${ }^{+}$ $\mathrm{T}$ cells recognize the Tax protein, the frequency of HBZ-specific $\mathrm{CD}^{+} \mathrm{T}$ cells is significantly lower (Macnamara et al., 2010). HBZ-expressing cells could thus escape lysis from a cytotoxic T lymphocyte (CTL) response and would consequently enhance viral persistence in infected people (Suemori et al., 2009; Macnamara et al., 2010). It has also been suggested that Tax can stimulate HBZ expression although this issue remains controversial, as most results were obtained from cell lines transfected with a Tax expression plasmid and reporter vectors containing only one HTLV-1 LTR (Larocca et al., 1989; Cavanagh et al., 2006; Yoshida et al., 2008; Landry et al., 2009). Indeed, such an effect by Tax has not been confirmed in T cells infected with a complete proviral DNA containing two LTRs (Belrose et al., 2011). Moreover, we have observed that activation of sense transcription from the $5^{\prime}$ LTR down-regulated the synthesis of antisense transcripts from the $3^{\prime}$ LTR (Cavanagh et al., 2006; Landry et al., 2007). It should also be emphasized that the regulation of $\mathrm{APH}-2$ expression in infected cells remains currently unknown.

\section{HBZ AND APH-2 REGULATE THE AP-1 PATHWAY IN A DIFFERENT MANNER}

In unstimulated T cells, basal protein levels of the AP-1 complex are low but there is a rapid induction of AP-1 activity after T cell stimulation. The AP-1 transcription complex has been shown to
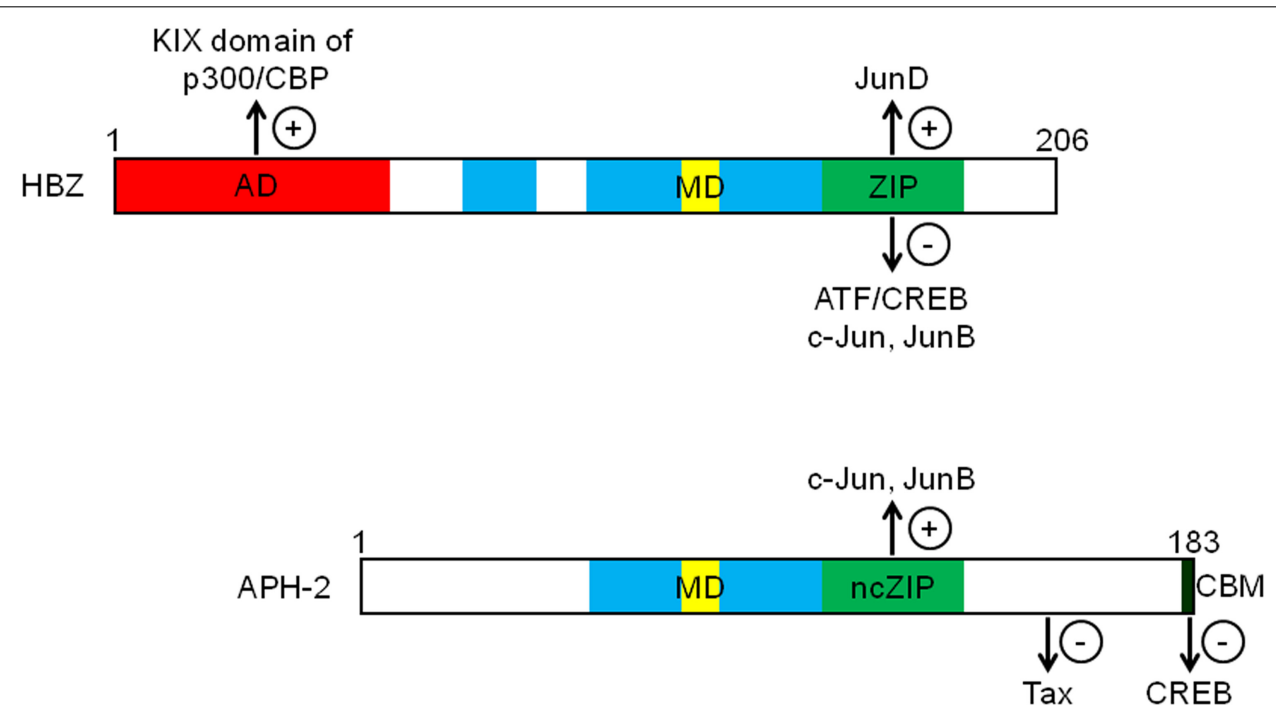

FIGURE 2 | Schematic representations of HBZ and APH-2 functional domains. Both proteins contain basic domains (blue) involved in their nuclear localization. HBZ possesses an N-terminal activation domain (AD in red), a modulatory domain (MD in yellow) and a ZIP (green) controlling the transcriptional activity of Jun and ATF/CREB proteins. While APH-2 does not contain any activation domain, it can interact with c-Jun and JunB through a non-canonical ZIP region (ncZIP in green) and with CREB through a C-terminal CREB-binding motif (CBM in black). Unlike HBZ, APH-2 binds to Tax $(+)$ and $(-)$ respectively indicate an activating or inhibiting effect of viral proteins on targeted proteins. 
be involved in the regulation of numerous cellular genes involved in lymphocyte activation. The AP-1 transcription factor consists of heterodimers between the Jun (c-Jun, JunB, and JunD) and Fos (c-Fos, FosB, Fra-1, and Fra-2) family members through their ZIP domains. AP-1 complexes are not limited to Jun and Fos dimers, since Jun and Fos proteins have been shown to dimerize with other bZIP proteins, including members of the ATF/CREB family and the Maf transcription factors. ATLL cells have been shown to contain constitutively activated AP- 1 complexes, which are mainly constituted of JunD (Mori et al., 2000). HBZ, via its ZIP domain, forms heterodimers with all the members of the Jun family (Basbous et al., 2003a; Thébault et al., 2004). The interaction of HBZ with c-Jun and JunB results in repression of their transcriptional activity through degradation or sequestration into transcriptionally inactive nuclear bodies (Basbous et al., 2003a; Matsumoto et al., 2005; Hivin et al., 2007; Clerc et al., 2009). On the other hand, the HBZ/JunD heterodimer can activate transcription of cellular genes such as the human telomerase catalytic subunit (hTERT) and the antiapoptotic Bfl-1 (Kuhlmann et al., 2007; Macaire et al., 2012). HBZ can also dysregulate other cellsignaling pathways such as FoxP3 (Satou et al., 2011), NF-кB (Zhao et al., 2009; Zhi et al., 2011; Wurm et al., 2012), TGF- $\beta$ (Zhao et al., 2011), and Wnt pathways (Ma et al., 2012). The resulting dysregulated pathways suggest that HBZ expression might play a central role in the development of ATLL and HAM/TSP through these altered transcription factors (Mesnard et al., 2006; Satou et al., 2006, 2011; Arnold et al., 2008; Zhi et al., 2011; Sugata et al., 2012).

Unlike HBZ, analysis of APH-2 does not predict a typical bZIP domain. However, APH-2 does interact with c-Jun and JunB through its non-canonical bZIP domain (Figure 2; Marban et al., 2012). Although inconsistently, APH-2 does not appear to bind to JunD in vivo (Marban et al., 2012). However, given the unique structure of its ZIP domain it is not surprising that APH-2 does not form canonical interactions with human bZIPs (Reinke etal., 2010). An interesting outcome from the interaction between APH-2 and the different Jun family members is that APH-2 potentiates their trans-activation activity (Marban et al., 2012). This is thereby in sharp contrast to the negative or positive modulation of $\mathrm{HBZ}$ on the various Jun factors. Interesting results from this study have also inferred a potential complex between Tax2B and APH-2 involving a region from amino acid 102 to 183 . As no competition occurred between Jun factors and Tax $2 \mathrm{~B}$ in their binding to $\mathrm{APH}-2$, the region of interaction for Tax2B is likely located outside the bZIP-like domain (Figure 2). Furthermore, the modulation of AP-1 activation by Tax2B was greatly reduced when APH-2 was co-expressed. However, the above experiments were conducted in overexpression condition and it will therefore be mandatory to confirm these data with physiologically relevant expression levels. These results highlight a very complex interplay between Tax 2 and APH-2 in relation to other transcription factors and it will be important to determine how this type of interaction is affected in the context of ATF/CREB family members. Furthermore, we have not observed that HBZ interacts with Tax (Hivin et al., 2005) and therefore further experiments will be required to address this issue.

\section{HBZ INDUCES IL-2-INDEPENDENT T CELL PROLIFERATION}

Based on the effect of HBZ on AP-1-dependent gene expression, HBZ might contribute to the dysregulation of cell proliferation in infected cells. In fact, two reports using HBZ-specific shRNA expression vectors have demonstrated that HBZ was important for the proliferation of HTLV-1-infected cell lines (Satou et al., 2006; Arnold et al., 2008). In these studies, although HBZ was not found to be required for HTLV-1-induced peripheral blood mononuclear cell (PBMC) immortalization, $\mathrm{HBZ}$ was shown to be important for cell proliferation of infected cells and had an impact in infection experiments in rabbits. Furthermore, along with these studies, other reports have determined that HBZ expression correlated with proviral DNA load, likely through its capacity to permit infected cells to proliferate (Arnold et al., 2008; Li et al., 2009). Based on these reports, HBZ has further been associated with ATLL development. Early implication of HBZ in ATLL development has been based on the occurrence of HBZ expression in ATLL cells from most tested patients (Satou et al., 2006; Usui et al., 2008). This is in contrast to Tax, whose expression is often repressed in ATLL cells. A balance between Tax and HBZ expression (Barbeau and Mesnard, 2011) might thereby be important to permit cells to proliferate and, in fact might be determinant in hampering previously reported Tax-mediated cell senescence (Zhi et al., 2011). More recent evidence has also permitted to suggest mechanisms by which HBZ could be implicated in ATLL, such as its induction of hTERT expression via a Sp1-dependent mechanism (Kuhlmann et al., 2007), its interaction with ATF-3 to suppress the ATF-3-induced p53 transcription activity stimulation (Hagiya et al., 2011), and the inhibition of p300/CBP acetyl transferase activity (Wurm et al., 2012). Additional data also argue for a potential oncogenic property of HBZ. Indeed, experiments in transgenic mice expressing $\mathrm{HBZ}$ in $\mathrm{CD}^{+}{ }^{+} \mathrm{T}$ cells resulted in high incidence of T cell lymphoma (Satou et al., 2011). In addition, NOD/SCID mice engrafted with HBZ-silenced HTLV-1-infected cells were less infiltrating and formed tumors at lesser extent than control infected cells (Arnold et al., 2008). We have also recently demonstrated that proviral DNA-expressed HBZ induced anchorage-independent growth in NIH 3T3 cells and correlated with induced JunD expression (Gazon et al., 2012). An intriguing observation also suggests that the HBZ transcript itself could be essential for induced IL2-independent $\mathrm{T}$ cell proliferation (Satou et al., 2006). Kinetics and intracellular compartmentalization study of HTLV-1 mRNA expression is indirectly favoring the implication of such a transcript in cell proliferation, as HBZ viral transcripts have been shown strongly sequestered in the nucleus when compared to other viral transcripts (Rende et al., 2011). However, these data have been obtained after transfection of HLtat cells with the HTLV-1 proviral clone ACH. When $293 \mathrm{~T}$ cells were similarly transfected, such a nuclear retention of HBZ mRNA was not confirmed (Li et al., 2012) showing that this observation strongly depends on the transfected cell line and has to be confirmed in physiologically relevant conditions.

Recent studies have compared the proliferation-inducing capacity of APH-2 to this functional characteristic of $\mathrm{HBZ}$ (Douceron et al., 2012). Although not associated with any forms of leukemia, HTLV-2 has nonetheless been linked to lymphocytosis in infected patients (Bartman et al., 2008). Certain similar features, 
reminiscent of a potential impact on cell proliferation, were noted when similar analyses were performed on APH-2. First, APH-2 expression has been detected in most PBMC samples of HTLV-2infected patients (Halin et al., 2009; Douceron et al., 2012). Second, a correlation between APH-2 expression levels and proviral DNA load was also noted (Douceron et al., 2012). Furthermore, a typical nuclear sequestration of its mRNA was inferred in both patient cells and infected cell lines (Bender et al., 2012). However, unlike $\mathrm{HBZ}, \mathrm{APH}-2$ is not capable of leading to IL-2-independent growth of IL-2-dependent cell lines (Douceron et al., 2012). Moreover, the absence of an impact on proliferation was further suggested in a study demonstrating no impact on proliferation of infected cells lines in addition to no effect on the immortalization capacity of HTLV-2 on infected PBMCs (Yin et al., 2012). In conclusion, no clear correlation between APH-2 mRNA expression, its nuclear retention, and HTLV-2-induced lymphocytosis was observed.

\section{PERSISTENCE OF HTLV-1 VS. HTLV-2 INFECTION IN RELATION TO THEIR RESPECTIVE ANTISENSE PROTEIN}

Using the rabbit model, a number of elegant studies have focussed on the consequence of HBZ silencing on HTLV-1 replication.
Although no drastic differences were noted in HTLV-1 infection and replication in cell culture conditions, infection of rabbits with irradiated HTLV-1-producing cells highlighted an important role of HBZ on HTLV-1 persistence, as indicated by anti-HTLV-1 antibody titers and proviral DNA loads (Arnold et al., 2006). When similar experiments were conducted with HTLV-2, again APH-2 did not alter viral replication in cell culture experiments. However, inoculation of rabbit with irradiated cells producing HTLV-2 virions deficient for APH-2 led to a higher and more sustained antibody response correlating with higher proviral load at certain time points (Yin et al., 2012). These results thereby argue that, unlike HBZ, APH-2 is not necessary for viral persistence but might instead be related to the reduced capacity of HTLV-2 infection.

Both HTLV-1 and HTLV-2 are able to establish a persistent infection in $\mathrm{CD}^{+}$and $\mathrm{CD}^{+}{ }^{+} \mathrm{T}$ cells but HTLV-1 establishes a more robust infection in $\mathrm{T}$ lymphocytes (Kannian et al., 2012). Moreover, infection results in an increase in proviral loads and viral expression such as Tax, Gag, and Env (Figure 3). However, cells highly expressing viral proteins are eliminated by the humoral response and CTL activity of the host

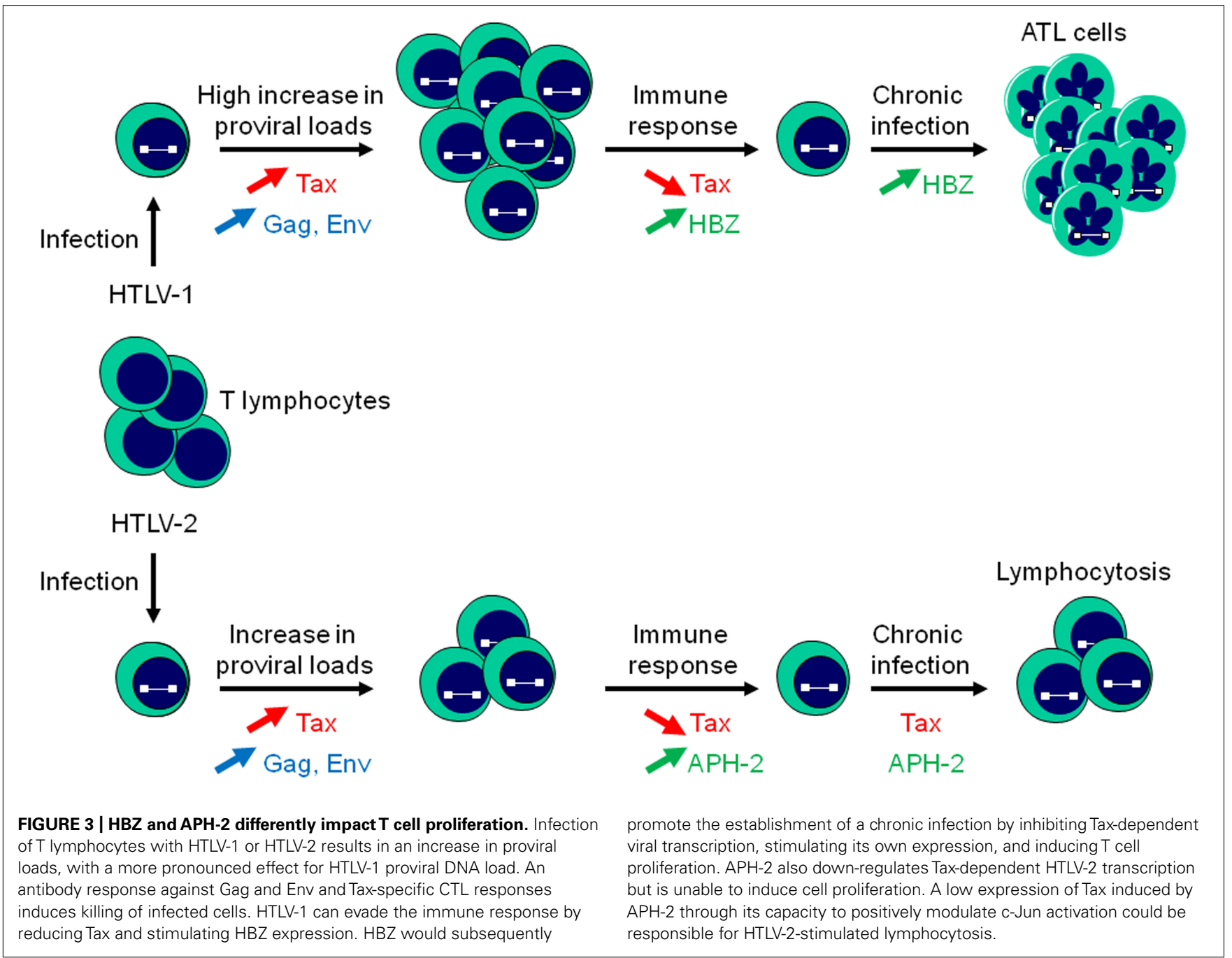


(Macnamara etal., 2010; Enose-Akahata et al., 2012; EnoseAkahata etal., 2013). At this stage, HBZ and APH-2 might play a crucial role by down-regulating Tax-dependent viral transcription and may allow infected cells to evade the immune response. In additionally, $\mathrm{HBZ}$ promotes the proliferation of infected T lymphocytes (Figure 3). This dual action probably confers a survival advantage on HBZ-expressing cells and is consistent with the observation that HBZ favors the establishment of persistent infection in HTLV-1-inoculated rabbits (Arnold et al., 2006). On the other hand, unlike HBZ, APH-2 is not required for viral persistence (Yin etal., 2012) and unable to promote lymphocytosis (Douceron et al., 2012). However, a low expression of Tax from the TxREs of the $5^{\prime}$ LTR induced by AP-1 transcriptional activity stimulated by APH-2 could explain lymphocytosis commonly observed in HTLV-2 carriers (Figure 3). Further experiments are definitely needed to better understand the mechanism by which HTLV-2 infection could lead to lymphocytosis.

\section{CONCLUSIONS AND PERSPECTIVES}

The discovery of HBZ has led to important new research avenues with potential association with HTLV-1-associated diseases. In fact, ATLL cells from infected patients consistently express HBZ and substantial evidence points toward its implication in viral persistence and ATLL cell survival. Recent evidences further suggest that HBZ lead toward a Treg phenotype. Future experiments will

\section{REFERENCES}

Albrecht, B., and Lairmore, M. D. (2002). Critical role of human $\mathrm{T}$ lymphotropic virus type 1 accessory proteins in viral replication and pathogenesis. Microbiol. Mol. Biol. Rev. 66, 396-406. doi: 10.1128/ MMBR.66.3.396-406.2002

Arnold, J., Yamamoto, B., Li, M., Phipps, A. J., Younis, I., Lairmore, M. D., et al. (2006). Enhancement of infectivity and persistence in vivo by $\mathrm{HBZ}$, a natural antisense coded protein of HTLV-1. Blood 107, 3976-3982. doi: 10.1182/blood-2005-11-4551

Arnold, J., Zimmerman, B., Li, M., Lairmore, M. D., and Green, P. L. (2008). Human T-cell leukemia virus type-1 antisense-encoded gene, Hbz, promotes T-lymphocyte proliferation. Blood 112, 3788-3797. doi: 10.1182/blood-2008-04-154286

Barbeau, B., and Mesnard, J. M. (2007). Does the HBZ gene represent a new potential target for the treatment of adult T-cell leukemia? Int. Rev. Immunol. 26, 283-304. doi: 10.1080/08830180701690843

Barbeau, B., and Mesnard, J. M. (2011). Making sense out of antisense transcription in human T-cell lymphotropic viruses (HTLVs). Viruses 3 , 456-468. doi: 10.3390/v3050456

Bartman, M. T., Kaidarova, Z., Hirschkorn, D., Sacher, R. A., Fridey, J., Garratty, G., et al.
(2008). Long-term increases in lymphocytes and platelets in human T-lymphotropic virus type II infection. Blood 112, 3995-4002. doi: 10.1182/blood-2008-05-155960

Basbous, J., Arpin, C., Gaudray, G., Piechaczyk, M., Devaux, C., and Mesnard, J. M. (2003a). HBZ factor of HTLV-I dimerizes with transcription factors JunB and c-Jun and modulates their transcriptional activity. $J$. Biol. Chem. 278, 43620-43627. doi: 10.1074/jbc.M307275200

Basbous, J., Bazarbachi, A., Granier, C., Devaux, C., and Mesnard, J. M. (2003b). The central region of human T-cell leukemia virus type 1 Tax protein contains distinct domains involved in subunit dimerization. J. Virol. 77, 1302813035. doi: 10.1128/JVI.77.24.1302813035.2003

Belrose, G., Gross, A., Olindo, S. Lezin, A., Dueymes, M., KomlaSoukha, I., et al. (2011). Opposite effects of valproate on Tax and HBZ expressions in T-lymphocytes from HTLV-1 asymptomatic carriers and HAM/TSP patients. Blood 118, 24832491. doi: 10.1182/blood-2010-11321364

Bender, C., Rende, F., Cotena, A., Righi, P., Ronzi, P., Cavallari, I., et al. (2012). Temporal regulation of HTLV-2 expression in infected cell lines and patients: evidence

be needed to determine if similar attributes can be given to APH-2. As $\mathrm{HBZ}$ and $\mathrm{APH}-2$ also differ mechanistically and functionally in their interaction with transcription factors such as Jun and CREB, it will be important to further expand on these differences and define the exact nature of these interactions. Several transcription factors known to interact with HBZ will also need to be analyzed in the context of APH-2 and in relation to the different cellular localizations of these proteins. In addition, the role played by HBZ on proliferation needs to be clarified as to how its transcript impacts IL-2-independent growth. These studies might also consider variation in the sequence of APH-2 transcripts, which could explain their different ability in inducing proliferation. Finally, these experiments should also be undertaken with equivalent antisense proteins of HTLV-3 and HTLV-4, i.e., APH-3 and APH-4 to determine how these proteins alter the various functions associated to HBZ. Finally, these comparative studies will provide a better understanding as to the mechanism by which HBZ is involved in ATLL development, which might also lead to new potential ATLL treatment.

\section{ACKNOWLEDGMENTS}

Jean-Michel Mesnard and Benoit Barbeau would like to thank for their support the Agence Nationale de Recherches sur le Sida et les Hépatites Virales (ANRS) and The Cancer Research Society, respectively. Benoit Barbeau holds a Canada Research Chair in human retrovirology (Tier 2).

for distinct expression kinetics with nuclear accumulation of APH-2 mRNA. Retrovirology 9, 74. doi: 10.1186/1742-4690-9-74

Boxus, M., Twizere, J. C., Legros, S., Dewulf, J. F., Kettmann, R., and Willems, L. (2008). The HTLV-1 Tax interactome. Retrovirology 5, 76. doi: 10.1186/1742-4690-5-76

Cavanagh, M.-H., Landry, S., Audet, B., Arpin-Andre, C., Hivin, P., Paré, M.-E., et al. (2006). HTLV-I antisense transcripts initiating in the $3^{\prime}$ LTR are alternatively spliced and polyadenylated. Retrovirology 3, 15 . doi: 10.1186/1742-4690-3-15

Clerc, I., Hivin, P., Rubbo, P. A., Lemasson, I., Barbeau, B., and Mesnard, J.M. (2009). Propensity for HBZ-SP1 isoform of HTLV-I to inhibit c-Jun activity correlates with sequestration of c-Jun into nuclear bodies rather than inhibition of its DNA-binding activity. Virology 391, 195-202. doi: 10.1016/j.virol.2009.06.027

Clerc, I., Polakowski, N., Andre-Arpin, C., Cook, P., Barbeau, B., Mesnard, J.-M., etal. (2008). An interaction between the human $\mathrm{T}$ cell leukemia virus type 1 basic leucine zipper factor (HBZ) and the KIX domain of p300/CBP contributes to the downregulation of tax-dependent viral transcription by HBZ. J. Biol. Chem. 283, 23903-23913. doi: 10.1074/jbc. M803116200
Cook, P. R., Polakowski, N., and Lemasson, I. (2011). HTLV-1 HBZ protein deregulates interactions between cellular factors and the KIX domain of p300/CBP. J. Mol. Biol. 409, 384-398. doi: 10.1016/ j.jmb.2011.04.003

Douceron, E., Kaidarova, Z., Miyazato, P., Matsuoka, M., Murphy, E. L., and Mahieux, R. (2012). HTLV2 APH-2 expression is correlated with proviral load but APH-2 does not promote lymphocytosis. J. Infect. Dis. 205, 82-86. doi: 10.1093/infdis/ jir708

Enose-Akahata, Y., Abrams, A., Johnson, K. R., Maloney, E. M., and Jacobson, S. (2012). Quantitative differences in HTLV-I antibody responses: classification and relative risk assessment for asymptomatic carriers and ATL and HAM/TSP patients from Jamaica. Blood 119, 2829-2836. doi: 10.1182/blood2011-11-390807

Enose-Akahata, Y., Abrams, A., Massoud, R., Bialuk, I., Johnson, K. R., Green, P. L., et al. (2013). Humoral immune response to HTLV-1 basic leucine zipper factor (HBZ) in HTLV1 -infected individuals. Retrovirology 10, 19 . doi: 10.1186/1742-469010-19

Feuer, G., and Green, P. L. (2005). Comparative biology of human T-cell lymphotropic virus type 1 (HTLV-1) 
and HTLV-2. Oncogene 24, 59966004. doi: 10.1038/sj.onc.1208971

Gachon, F., Devaux, C., and Mesnard, J. M. (2002). Activation of HTLV-I transcription in the presence of Tax is independent of the acetylation of CREB-2 (ATF-4). Virology 299, 271278. doi: 10.1006/viro.2002.1501

Gaudray, G., Gachon, F., Basbous, J., Biard-Piechaczyk, M., Devaux, C., and Mesnard, J. M. (2002). The complementary strand of HTLV-1 RNA genome encodes a bZIP transcription factor that down-regulates the viral transcription. J. Virol. 76, 12813 12822. doi: 10.1128/JVI.76.24.1281312822.2002

Gazon, H., Lemasson, I., Polakowski, N., Cesaire, R., Matsuoka, M., Barbeau, B., etal. (2012). Human Tcell leukemia virus type 1 (HTLV-1) bZIP factor requires cellular transcription factor JunD to upregulate HTLV-1 antisense transcription from the $3^{\prime}$ long terminal repeat. J. Virol. 86, 9070-9078. doi: 10.1128/JVI. 00661-12

Hagiya, K., Yasunaga, J., Satou, Y., Ohshima, K., and Matsuoka, M. (2011). ATF3, an HTLV-1 bZip factor binding protein, promotes proliferation of adult T-cell leukemia cells. Retrovirology 8, 19. doi: 10.1186/1742-4690-8-19

Halin, M., Douceron, E., Clerc, I., Journo, C., Ko, N. L., Landry, S., et al. (2009). Human T-cell leukemia virus type 2 produces a spliced antisense transcript encoding a protein that lacks a classical bZIP domain but still inhibits Tax2-mediated transcription. Blood 114, 2427-2437. doi: 10.1182/blood-2008-09-179879

Hanon, E., Hall, S., Taylor, G. P., Saito, M., Davis, R., Tanaka, Y., et al. (2000). Abundant tax protein expression in $\mathrm{CD}^{+} \mathrm{T}$ cells infected with human $\mathrm{T}$-cell lymphotropic virus type I (HTLV-I) is prevented by cytotoxic T lymphocytes. Blood 95, 13861392.

Hivin, P., Arpin-André, C., Clerc, I., Barbeau, B., and Mesnard, J. M. (2006). A modified version of a Fos-associated cluster in HBZ affects Jun transcriptional potency. Nucleic Acids Res. 34, 2761-2772. doi: 10.1093/nar/gkl375

Hivin, P., Basbous, J., Raymond, F., Henaff, D., Arpin-Andre, C., RobertHebmann, V., et al. (2007). The HBZ-SP1 isoform of human T-cell leukemia virus type I represses JunB activity by sequestration into nuclear bodies. Retrovirology 4, 14. doi: 10.1186/1742-4690-4-14

Hivin, P., Frédéric, M., Arpin-André, C., Basbous, J., Gay, B., Thébault,
S., et al. (2005). Nuclear localization of HTLV-I bZIP factor (HBZ) is mediated by three distinct motifs. J. Cell Sci. 118, 1355-1362. doi: $10.1242 /$ jcs. 01727

Imai, M., Higuchi, M., Kawamura, H., Yoshita, M., Takahashi, M., Oie, M., etal. (2012). Human T cell leukemia virus type 2 (HTLV-2) Tax2 has a dominant activity over HTLV1 Tax1 to immortalize human CD4+ T cells. Virus Genes 46, 39-46. doi: 10.1007/s11262-012-0831-9

Kannian, P., Yin, H., Doueiri, R., Lairmore, M. D., Fernandez, S., and Green, P. L. (2012). Distinct transformation tropism exhibited by human $\mathrm{T}$ lymphotropic virus type 1 (HTLV-1) and HTLV-2 is the result of postinfection T cell clonal expansion. J. Virol. 86, 3757-3766. doi: 10.1128/JVI.06900-11

Kuhlmann, A. S., Villaudy, J., Gazzolo, L., Castellazzi, M., Mesnard, J. M., and Duc Dodon, M. (2007). HTLV1 HBZ cooperates with JunD to enhance transcription of the human telomerase reverse transcriptase gene (hTERT). Retrovirology 4, 92. doi: 10.1186/1742-4690-4-92

Landry, S., Halin, M., Lefort, S., Audet, B., Vaquero, C., Mesnard, J. M., et al. (2007). Detection, characterization, and regulation of antisense transcripts in HIV-1. Retrovirology 4, 71. doi: 10.1186/1742-46904-71

Landry, S., Halin, M., Vargas, A., Lemasson, I., Mesnard, J. M., and Barbeau, B. (2009). Upregulation of human Tcell leukemia virus type 1 antisense transcription by the viral tax protein. J. Virol. 83, 2048-2054. doi: 10.1128/JVI.01264-08

Larocca, D., Chao, L. A., Seto, M. H., and Brunck, T. K. (1989). Human T-cell leukemia virus minus strand transcription in infected T-cells. Biochem. Biophys. Res. Commun. 163, 1006-1013. doi: 10.1016/0006291X(89)92322-X

Larocque, E., Halin, M., Landry, S., Marriott, S., Switzer, W. M., and Barbeau, B. (2011). HTLV-3- and HTLV-4derived antisense transcripts encode proteins with similar Tax-inhibiting function but distinct subcellular localization. J. Virol. 85, 1267312684. doi: 10.1128/JVI.05296-11

Lemasson, I., Lewis, M. R., Polakowski, N., Hivin, P., Cavanagh, M. H., Thebault, S., et al. (2007). Human T-cell leukemia virus type 1 (HTLV-1) bZIP protein interacts with the cellular transcription factor CREB to inhibit HTLV-1 transcription. J. Virol. 81, 1543-1553. doi: 10.1128/JVI. 00480-06
Li, M., Kannian, P., Yin, H., Kesic, M., and Green, P. L. (2012). Human T lymphotropic virus type 1 regulatory and accessory gene transcript expression and export are not rex dependent. AIDS Res. Hum. Retroviruses 28, 405-410. doi: 10.1089/aid.2011.0130

Li, M., Kesic, M., Yin, H., Yu, L., and Green, P. L. (2009). Kinetic analysis of human T-cell leukemia virus type 1 gene expression in cell culture and infected animals. J. Virol. 83, 37883797. doi: 10.1128/JVI.02315-08

Luebben, W. R., Sharma, N., and Nyborg, J. K. (2010). Nucleosome eviction and activated transcription require p300 acetylation of histone H3 lysine 14. Proc. Natl. Acad. Sci. U.S.A. 107, 19254-19259. doi: 10.1073/pnas.1009650107

Ma, G., Yasunaga, J., Fan, J., Yanagawa, S., and Matsuoka, M. (2012). HTLV-1 bZIP factor dysregulates the Wnt pathways to support proliferation and migration of adult $\mathrm{T}$ cell leukemia cells. Oncogene doi: 10.1038/onc.2012.450 [Epub ahead of print].

Macaire, H., Riquet, A., Moncollin, V., Biemont-Trescol, M. C., Duc Dodon, M., Hermine, O., et al. (2012). Tax protein-induced expression of antiapoptotic Bfl-1 protein contributes to survival of human T-cell leukemia virus type 1 (HTLV-1)-infected T-cells. J. Biol. Chem. 287, 21357-21370. doi: 10.1074/jbc.M112.340992

Macnamara, A., Rowan, A., Hilburn, S., Kadolsky, U., Fujiwara, H., Suemori, K., et al. (2010). HLA class I binding of $\mathrm{HBZ}$ determines outcome in HTLV-1 infection. PLoS Pathog. 6:e1001117. doi: 10.1371/journal.ppat.1001117

Marban, C., McCabe, A., Bukong, T. N., Hall, W. W., and Sheehy, N. (2012). Interplay between the HTLV-2 Tax and $\mathrm{APH}-2$ proteins in the regulation of the AP-1 pathway. Retrovirology 9, 98. doi: 10.1186/1742-4690-9-98

Matsumoto, J., Ohshima, T., Isono, O., and Shimotohno, K. (2005). HTLV1 HBZ suppresses AP-1 activity by impairing both the DNA-binding ability and the stability of c-Jun protein. Oncogene 24, 1001-1010. doi: 10.1038/sj.onc. 1208297

Matsuoka, M., and Jeang, K. T. (2007). Human T-cell leukaemia virus type 1 (HTLV-1) infectivity and cellular transformation. Nat. Rev. Cancer 7, 270-280. doi: 10.1038/nrc2111

Mesnard, J. M., Barbeau, B., and Devaux, C. (2006). HBZ, a new important player in the mystery of Adult-T-cell leukemia. Blood
108, 3979-3982. doi: 10.1182/blood2006-03-007732

Mesnard, J. M., and Devaux, C. (1999). Multiple control levels of cell proliferation by human T-cell leukemia virus type 1 Tax protein. Virology 257, 277-284. doi: 10.1006/viro.1999.9685

Miyoshi, I., Kubonishi, I., Yoshimoto, S., Akagi, T., Ohtsuki, Y., Shiraishi, Y., et al. (1981). Type C virus particles in a cord $\mathrm{T}$ cell line derived by co-cultivating normal human cord leukocytes and human leukaemic $\mathrm{T}$ cells. Nature 294, 770-771. doi: 10.1038/294770a0

Mori, N., Fujii, M., Iwai, K., Ikeda, S., Yamasaki, Y., Hata, T., et al. (2000). Constitutive activation of transcription factor AP-1 in primary adult T-cell leukemia cells. Blood 95, 39153921.

Murata, K., Hayashibara, T., Sugahara, K., Uemura, A., Yamaguchi, T., Harasawa, H., et al. (2006). A novel alternative splicing isoform of human T-cell leukemia virus type 1 bZIP factor (HBZ-SI) targets distinct subnuclear localization. J. Virol. 80, 2495-2505. doi: 10.1128/JVI.80.5.2495-2505.2006

Nyborg, J. K., Egan, D., and Sharma, N. (2010). The HTLV1 Tax protein: revealing mechanisms of transcriptional activation through histone acetylation and nucleosome disassembly. Biochim. Biophys. Acta 1799, 266-274. doi: 10.1016/j.bbagrm.2009.09.002

Poiesz, B. J., Ruscetti, F. W., Gazdar, A. F., Bunn, P. A., Minna, J. D., and Gallo, R. C. (1980). Detection and isolation of type $\mathrm{C}$ retrovirus particles from fresh and cultured lymphocytes of a patient with cutaneous T-cell lymphoma. Proc. Natl. Acad. Sci. U.S.A. 77, 7415-7419. doi: 10.1073/pnas.77.12.7415

Polakowski, N., Gregory, H., Mesnard, J. M., and Lemasson, I. (2010). Expression of a protein involved in bone resorption, Dkk1, is activated by HTLV-1 bZIP factor through its activation domain. Retrovirology 7, 61. doi: 10.1186/1742-4690-7-61

Reinke, A. W., Grigoryan, G., and Keating, A. E. (2010). Identification of bZIP interaction partners of viral proteins HBZ, MEQ, BZLF1, and K-bZIP using coiled-coil arrays. Biochemistry 49, 1985-1997. doi: 10.1021/bi902065k

Rende, F., Cavallari, I., Corradin, A., Silic-Benussi, M., Toulza, F., Toffolo, G. M., et al. (2011). Kinetics and intracellular compartmentalization of HTLV-1 gene expression: nuclear retention of HBZ mRNAs. Blood 
117, 4855-4859. doi: 10.1182/blood2010-11-316463

Satou, Y., Yasunaga, J.-I., Yoshida, M., and Matsuoka, M. (2006). HTLV-I basic leucine zipper factor gene mRNA supports proliferation of adult T cell leukemia cells. Proc. Natl. Acad. Sci. U.S.A. 103, 720-725. doi: 10.1073/pnas.0507631103

Satou, Y., Yasunaga, J., Zhao, T., Yoshida, M., Miyazato, P., Takai, K., etal. (2011). HTLV1 bZIP factor induces T-cell lymphoma and systemic inflammation in vivo. PLoS Pathog. 7:e1001274. doi: 10.1371/journal.ppat.1001274

Suemori, K., Fujiwara, H., Ochi, T., Ogawa, T., Matsuoka, M., Matsumoto, T., etal. (2009). $\mathrm{HBZ}$ is an immunogenic protein, but not a target antigen for human T-cell leukemia virus type 1-specific cytotoxic T lymphocytes. J. Gen. Virol. 90, 1806-1811. doi: 10.1099/vir.0.010199-0

Sugata, K., Satou, Y., Yasunaga, J., Hara, H., Ohshima, K., Utsunomiya, A., et al. (2012). HTLV-1 bZIP factor impairs cell-mediated immunity by suppressing production of Th1 cytokines. Blood 119, 434444. doi: 10.1182/blood-2011-05357459

Takeda, S., Maeda, M., Morikawa, S., Taniguchi, Y., Yasunaga, J., Nosaka,
K., et al. (2004). Genetic and epigenetic inactivation of tax gene in adult T-cell leukemia cells. Int. J. Cancer 20, 559-567. doi: 10.1002/ijc.20007

Thébault, S., Basbous, J., Hivin, P., Devaux, C., and Mesnard, J. M. (2004). HBZ interacts with JunD and stimulates its transcriptional activity. FEBS Lett. 562, 165170. doi: 10.1016/S0014-5793(04) 00225-X

Usui, T., Yanagihara, K., Tsukasaki, K., Murata, K., Hasegawa, H., Yamada, Y., et al. (2008). Characteristic expression of HTLV-1 basic zipper factor (HBZ) transcripts in HTLV1 provirus-positive cells. Retrovirology 5, 34. doi: 10.1186/17424690-5-34

Wurm, T., Wright, D. G., Polakowski, N., Mesnard, J. M., and Lemasson, I. (2012). The HTLV-1-encoded protein HBZ directly inhibits the acetyl transferase activity of p300/CBP. Nucleic Acids Res. 40, 5910-5925. doi: 10.1093/nar/gks244

Ye, J., Xie, L., and Green, P. L. (2003) Tax and overlapping rex sequences do not confer the distinct transformation tropisms of human $\mathrm{T}$ cell leukemia virus types 1 and 2. J. Virol. 77, 7728-7735. doi: 10.1128/JVI.77.14.7728-7735.2003

Yin, H., Kannian, P., Dissinger, N. Haines, R., Niewiesk, S., and Green,
P. L. (2012). Human T-cell leukemia virus type 2 antisense viral protein 2 is dispensable for in vitro immortalization but functions to repress early virus replication in vivo. J. Virol 86, 8412-8421. doi: 10.1128/JVI 00717-12

Yoshida, M., Satou, Y., Yasunaga, J., Fujisawa, J.-I., and Matsuoka, M. (2008). Transcriptional control of spliced and unspliced HTLV-1 bZIP factor gene. J. Virol. 82, 9359-9368. doi: 10.1128/JVI.00242-08

Zhao, T., Satou, Y., Sugata, K., Miyazato, P., Green, P. L., Imamura, T., et al. (2011). HTLV-1 bZIP factor enhances TGF-beta signaling through p300 coactivator. Blood 118, 1865-1876. doi: 10.1182/blood2010-12-326199

Zhao, T., Yasunaga, J., Satou, Y., Nakao, M., Takahashi, M., Fujii, M. et al. (2009). Human T-cell leukemia virus type 1 bZIP factor selectively suppresses the classical pathway of NF-kappaB. Blood 113, 2755 2764. doi: 10.1182/blood-2008-06161729

Zhi, H., Yang, L., Kuo, Y. L., Ho, Y. K., Shih, H. M., and Giam, C. Z. (2011). NF-kappaB hyper-activation by HTLV-1 Tax induces cellular senescence, but can be alleviated by the viral antisense protein HBZ. PLoS Pathog. 7e1002025. doi: 10.1371/journal. ppat. 1002025

Conflict of Interest Statement: The authors declare that the research was conducted in the absence of any commercial or financial relationships that could be construed as a potential conflict of interest.

Received: 10 May 2013; paper pending published: 03 June 2013; accepted: 25 July 2013; published online: 07 August 2013. Citation: Barbeau B, Peloponese J-M and Mesnard J-M (2013) Functional comparison of antisense proteins of $H T L V$ 1 and HTLV-2 in viral pathogenesis. Front. Microbiol. 4:226. doi: 10.3389/ fmicb.2013.00226

This article was submitted to Frontiers in Virology, a specialty of Frontiers in Microbiology.

Copyright: (c) 2013 Barbeau, Peloponese and Mesnard. This is an open-access article distributed under the terms of the Creative Commons Attribution License (CC BY). The use, distribution or reproduction in other forums is permitted, provided the original author(s) or licensor are credited and that the original publication in this journal is cited, in accordance with accepted academic practice. No use, distribution or reproduction is permitted which does not comply with these terms. 